\title{
Bronchoscopic lung volume reduction in chronic obstructive pulmonary disease: History and progress
}

\author{
Gang Hou \\ Department of Respiratory Medicine, First Affiliated Hospital of China Medical University, \\ Shenyang 110001, China
}

\section{ABSTRACT}

Emphysema is one of the pathological manifestations of chronic obstructive pulmonary disease (COPD), which leads to lung hyperinflation, decreased activity of the diaphragm, decreased compliance of the lung, and difficulties in gas exchange. The clinical effect of pharmacological treatment for patients with severe emphysema is limited. In recent years, the emergence of bronchoscopic lung volume reduction (BLVR) has opened up the possibility for the management of COPD with severe emphysema. The article aims to summarize the development, procedure, and methodology of BLVR as well as its clinical efficacy.

Key words: chronic obstructive pulmonary disease, emphysema, bronchoscopic lung volume reduction

\section{INTRODUCTION}

Emphysema is one of the symptoms of chronic obstructive pulmonary disease (COPD), which results in lung hyperinflation, decreased activity of the diaphragm, reduced pulmonary elastic recoil, and breathing difficulties. With the progression of the disease, patients often complain of shortness of breath after exertion, reduced exercise tolerance, and decreased quality of life. However, the clinical effect of pharmacological treatments on the symptoms of patients with severe emphysema such as breathing difficulties and forced expiratory volume in 1 second $\left(\mathrm{FEV}_{1}\right)$ is limited, so nonpharmacological treatments have been a topic of intense debate. ${ }^{[1-2]}$

Lung volume reduction surgery (LVRS) was first described by Dr. Brantigan in 1956. He proposed to remove partial lung tissue to increase lung compliance, respiratory functions, exercise tolerance, and quality of life. LVRS improves exercise tolerance and the survival rate of patients with heterogeneous upper lobe emphysema and poor baseline exercise tolerance. However,
LVRS causes relatively higher mortality and complication rates. Among patients who receive LVRS, the mortality rate within 90 days is $4 \%$; $46 \%$ need intercostal drainage for over 7 days; $11 \%$ are complicated with pulmonary infection; 7\% need intubation and mechanical ventilation; $6 \%$ need further surgery. Research shows some patients benefit from LVRS, which has motivated studies on minimally invasive operations. In 2003, it was reported that the bronchoscopic implantation of punctum plug in target lung lobe achieved desirable clinical efficacy.

\section{BLVR-RELATED ISSUES}

\section{Indications and contraindications}

The indications for BLVR are mainly based on the studies on LVRS. Most clinical studies suggest that the inclusion criteria contain the following: (1) stable COPD patients who have received conventional treatments for over 6 weeks; (2) FEV \% $\%$ pred: 15\% 45\%; (3) residual volume (RV) \%pred $>150 \%$; total lung capacity (TLC) $\%$ pred > $100 \%$; the volumes are measured by body plethysmograph; (4) after rehabilitation training, 6 minute walk distance (6MWD) 
$>140 \mathrm{~m}$; (5) static $\mathrm{PaCO}_{2}<55 \mathrm{mmHg}(1 \mathrm{mmHg}=0.133$ $\mathrm{kPa}$ ), $\mathrm{PaO}_{2}>45 \mathrm{mmHg}$; (6) emphysema shown by lung computerized tomography (CT) $\cdot^{[3-4]}$ The contraindications include the followings: (1) smokers; (2) active respiratory infection; (3) diffusing capacity of the lung for carbon monoxide $\left(\mathrm{DL}_{\mathrm{CO}}\right)<20 \%$; (4) severe heart disease or pulmonary artery hypertension.

\section{Pre-operational considerations}

It is essential to evaluate heterogeneous emphysema before BLVR. The studies on LVRS and BLVR show heterogeneous emphysema is one of the factors affecting the efficacy. ${ }^{[5-6]}$ Heterogeneous emphysema is confirmed if the difference between the percentage of low attenuation area $(\mathrm{LAA} \%)$ of the target lobe and that of the non-target is greater than $15 \%$. Or, LAA $\%$ is initially converted to values: 1\% 25\%: 1; 25\% 50\%: 2; 50\% 75\%: 3; 75\% 100\%: 4 . Heterogeneous emphysema is confirmed if the difference between the value of the low target lobe and that of the non-target is greater than $1^{[7]}$. Recent studies show patients with homogeneous emphysema can also benefit from BLVR, especially targeting at lobes with low perfusion during the baseline period. ${ }^{[7-8]}$

The collateral ventilation (CV) of target lobe affects occluded BLVR, but not non-occluded BLVR. ${ }^{[9-10]} \mathrm{CV}$ is commonly detected by the measurement of upper interlobar fissure integrity by lung high-resolution CT (HRCT) or by Chartis System (Switzerland). Fissure integrity is defined as "the completeness of the fissure (more than $90 \%$ of the fissure present on thin-slice HRCT) on at least one axis (sagittal, axial, or coronal views)."[10] Chartis System tests lobar exhaled air by Foley's catheter to determine whether $\mathrm{CV}$ exists. Negative results suggest the target lobe has no CV or low CV. The two methods for $\mathrm{CV}$ are equally acute and specific, ${ }^{[11]}$ so physicians can choose either of them based on the medical conditions of the patient.

\section{COMMON BLVR TECHNIQUES}

\section{Endobronchial valve (EBV)}

An EBV, similar to a bronchial stent, is a one-way valve, which is implanted in the target bronchus to occlude it so that during exhalation, the air within the target lobe comes out of the body, while during inhalation, the air pressure closes the valve to block the air from the target lobe, thereby reducing the lung volume. Presently, there are two types of EBV: IBV (intrabronchial valve, Olympus, Japan) and Zephyr EBV (Pulmonx International SARL, Switzerland). The two differ with respect to the one-way valve. IBV is made of an umbrella-shaped alloy frame with polymer membrane, which remains close to the airway wall when the stents are set up. Such valves are affected by IBV and the airway wall. Zephyr EBV contains a duckbilled one-way valve, whose function is not influenced by the airway wall.

\section{IBV}

In 2009, the clinical trial on 98 cases by Springmeyer et al. showed the quality of life was improved in 56\% patients; yet, lung function and exercise tolerance were not improved within a short time. ${ }^{[12]}$ In 2014, a multicenter randomized double-blind trial showed there are more responders in the treatment group than in the control group. This trial had technical and statistical success but did not obtain clinically meaningful results, which may be caused by patient selection, so further studies are needed to verify its efficacy. ${ }^{[13]}$ Now an open study on IBV after the detection of CV by Chartis System (clinical trial registry number: NCT01902732) is under way, which is expected to verify the efficacy of IBV and determine the selection criteria for an optimal indicated group.

\section{Zephyr EBV}

Zephyr EBV is the earliest and most widely used valve. The silicone membrane of the frame can remain tightly close to the airway wall. Besides, the valve is not easy to move once implanted due to the stabilizer. Several studies have proved the efficacy of BLVR with Zephyr EBV ${ }^{[8,14]}$ In 2010, the VENT study showed that, compared with the control group, there was an increase of $6.8 \%$ at 6 months, a decrease of $3.4 \%$ in St. George's respiratory questionnaire (SGRQ) score, an increase of $5.8 \%$ in $6 \mathrm{MWD}$, and an improvement in BODE index and breathing difficulty in the EBV group; the differences are statistically significant ${ }^{[10]}$. In addition, it has been found that highly heterogeneous emphysema, post-operative complete lobar occlusion and interlobar completeness or being without $\mathrm{CV}$ are the key factors affecting the clinical efficacy. The results of the European VENT study are similar to those of VENT. Clinically meaningful results have been obtained from the EBV group in terms of improved lung capacity, reduced target lobe volume, improved quality of life, and better exercise tolerance, compared with the control group. ${ }^{[8]}$ It has also been found that highly heterogeneous emphysema is not the only indication for EBV; homogeneous emphysema patients with interlobar completeness or without CV could benefit from EBV. The study provides new evidence for optimal indications for EBV.

BLVR with EBV is safe. The VENT study shows the differences between EBV and control group in major complications 3 and 12 months after the treatment including death are not statistically significant; EBV did not incur death. ${ }^{[8]}$ Common complications are acute exacerbation of COPD, pneumothorax, hemoptysis, valve displacement, and so on. ${ }^{[15-16]}$ A severe complication, pneumothorax is one of the predicative factors for efficacy. In most cases, it 
can be controlled by closed chest drainage, the procedures of which are detailed by European experts. ${ }^{[17-18]}$

\section{LVRC}

LVRC (PneumRx, USA) is made of Nickel titanium alloy. ${ }^{[1]]}$ When it is implanted in the target bronchus, the coil reverts to its original shape; in the meantime, the target bronchus and lobe bend and condense. A prospective cohort study shows $F_{1}$, RV, 6MWD, and SGRQ scores of COPD patients with heterogeneous emphysema have improved 6 months after LVRC treatment. ${ }^{[19]}$ LVRC, not influenced by $\mathrm{CV}$, is indicated for various severe COPD patients with heterogeneous emphysema. The relevant studies on homogeneous emphysema are rare. A large-scale study on the efficacy of LVRC in the treatment of homogeneous emphysema is being undertaken (clinical trial registry number: NCT01421082). No adverse events occurred during the operation; common post-operative events such as acute exacerbation of COPD, pneumothorax, slight hemoptysis, transient chest pain, and pneumonia have disappeared automatically or after the treatment; no lifethreatening events have occurred. The long-term efficacy and safety of LVRC need more support from evidencebased medicine.

\section{BioLVR}

BioLVR or polymeric lung volume reduction (PLVR) is the bronchoscopic instillation of gel into the target lobe aiming to block the lung tissues. AeriSeal (Aeris Therapeutics, Woburn, MA, USA) is a foam-like liquid occluder, which is used in bronchioles and alveoli with $10 \mathrm{~mL}$ (low dosage) or $20 \mathrm{~mL}$ (high dosage) for each subsegment. ${ }^{[20]}$ BioLVR is applicable to heterogeneous emphysema as well as homogeneous emphysema. For patients with the latter, low perfusion lobes should be chosen as target lobes. In a stage II multicenter clinical trial by Refaely et al., ${ }^{[21]}$ 28 patients with double upper lobar heterogeneous emphysema received low-dose PLVR and 22 patients with the same condition received high-dose PLVR. Six months later, improved lung capacity and quality of life were observed in both groups; the high-dose group presented better results. Magnussen et al..$^{[22]}$ have found interlobar fissure completeness could not affect the efficacy. PLVR could reduce lung volume, and improve lung function and exercise tolerance in heterogeneous emphysema patients with or without complete interlobar fissure. Another study on the efficacy of PLVR in the treatment of patients with homogeneous emphysema shows the technique could improve lung function, alleviate symptoms, and enhance the quality of life. ${ }^{[2]}$ PLVR is a new, safe, and effective BLVR technique with a wide range of application. However, the studies on this technique have used small samples and short follow-up, so its long-term efficacy and safety need to be investigated. ${ }^{[22]}$

\section{BTVA}

BTVA is a technique that blocks the target bronchus by Foley's tube, through which thermal vapor is introduced to induce an acute inflammatory response with resultant scarring, repair, and adhesion to reduce lung volume. ${ }^{[23]} \mathrm{A}$ study by Gompelmann et al., ${ }^{[24]}$ in which BTVA is used in the treatment of 44 patients with heterogeneous emphysema, has found greatly improved lung function, quality of life, and exercise tolerance. The inflammatory response reaches its peak from week 2 to week 4 , and reduces during week 8 and week 12. The inflammatory indicators such as C-reaction protein peak within 4 weeks. This study has established the efficacy and safety of BTVA. In addition, a Person correlation indicates interlobar fissure does not or slightly affect the reduced volume following BTVA and clinical indicators. The result suggests that BTVA alleviates the symptoms of emphysema patients regardless of CV, so it can be used to treat heterogeneous emphysema patients with incomplete interlobar fissure or patients who fail to respond to EBV because of $\mathrm{CV}$.

\section{Airway bypass stents (ABS)}

ABS, mainly used for severe homogeneous emphysema, is used to release the air trapped in emphysema area by bypasses. A small-scale study shows ABS can improve lung function and alleviate breathing difficulties; yet, no statistically significant results have been obtained. ${ }^{[25]}$ In a multi-center, randomized double-blind control trial on exhale airway stents for emphysema (EASE) in 2011, 315 patients with severe homogeneous emphysema were randomly divided into ABS group (208 cases) and control group (107 cases) and followed up at 1, 3, 6, 12 months for lung ventilation, 6MWD, and SGRQ score. The differences between the two groups in the endpoints are not statistically significant. ABS failed to reach the main endpoints. Compared with the baseline points, there is an increase of $12 \%$ in $\mathrm{FEV}_{1} \%$ pred 6 months after the operation, and an increase of 1 score in modified British Medical Research Council (mMRC). ${ }^{[26]}$ The study suggests ABS is effective for a short term; with the passage of time, the efficacy fades away. The loss of efficacy may be caused by such factors as ABS displacement, blockage of ABS by mucus plug, and granuloma formation that prevent the bypass from being open. Therefore, further study is needed to optimize ABS structure to maintain its long-term efficacy.

\section{PROSPECTS}

BLVR is of great importance in the treatment of COPD patients with severe emphysema, as its efficacy and safety have been proved by many studies. It is recommended by the Global Initiative for Chronic Obstructive Lung Disease (GOLD). At present, novel BLVR techniques such 
as hot saline abatement and autologous blood occlusion keep emerging. Yet, the long-term efficacy and optimal indications remain to be further studied. In China, only EBV has been ratified; another occluded BLVR-IBV is to be ratified, while non-occluded techniques are not allowed. Therefore, the choice of BLVR is limited and the treatment cost is high. As translational medicine is widely accepted, it is hoped that Chinese interventional pulmonologists and medical instrument companies will work together to develop BLVR techniques and products that are suitable for the country and its people so that more COPD patients with severe emphysema can receive effective treatment.

\section{Conflicts of Interest}

None declared.

\section{REFERENCES}

1. Marrero S, Adashi EY. Noncommunicable diseases. Semin Reproduct Med 2015; 33: 35-40.

2. Lee JH, Lee YK, Kim EK, Hyung KT, Hun JW, Kim WJ, et al. Responses to inhaled long-acting betaagonist and corticosteroid according to COPD subtype. Respir Med 2010; 104: 542-9.

3. Mineshita M, Slebos DJ. Bronchoscopic interventions for chronic obstructive pulmonary disease. Respirology 2014; 19: 1126-37.

4. Davey C, Zoumot Z, Jordan S, Carr DH, Polkey MI, Shah PL, et al. Bronchoscopic lung volume reduction with endobronchial valves for patients with heterogeneous emphysema and intact interlobar fissures (The BeLieVeR-HIFi trial): study design and rationale. Thorax 2015;70:288-90.

5. Herth FJ, Gompelmann D, Ernst A, Eberhardt R. Endoscopic lung volume reduction. Respiration 2010; 79: 5-13.

6. Herth FJ, Ernst A, Baker KM, Egan JJ, Gotfried MH, Hopkins P, et al. Characterization of outcomes 1 year after endoscopic thermal vapor ablation for patients with heterogeneous emphysema. Int J Chron Obstruct pulmon Dis 2012; 7: 397-405.

7. Eberhardt R, Gompelmann D, Schuhmann M, Heussel CP, Herth FJ. Complete unilateral vs partial bilateral endoscopic lung volume reduction in patients with bilateral lung emphysema. Chest 2012; 142: 900-8.

8. Herth FJ, Noppen M, Valipour A, Leroy S, Vergnon JM, Ficker JH, et al. Efficacy predictors of lung volume reduction with Zephyr valves in a European cohort. Eur Respir J 2012; 39: 1334-42.

9. Cohen E. Bronchoscopic treatment of end-stage chronic obstructive pulmonary disease. Curr Opin Anaesthesiol 2014; 27: 36-43.

10. Sciurba FC, Ernst A, Herth FJ, Strange C, Criner GJ, Marquette CH, et al. A randomized study of endobronchial valves for advanced emphysema. N Engl J Med, 2010; 363: 1233-44.

11. Gompelmann D, Eberhardt R, Slebos DJ, Brown MS, Abtin F, Kim HJ, et al. Diagnostic performance comparison of the Chartis System and high-resolution computerized tomography fissure analysis for planning endoscopic lung volume reduction. Respirology 2014; 19: 524-30.

12. Springmeyer SC, Bolliger CT, Waddell TK, Gonzalez X, Wood DE; IBV Valve Pilot Trials Research Teams. Treatment of heterogeneous emphysema using the spiration IBV valves. Thorac surg Clin 2009; 19: 247-53, ix-x.

13. Wood DE, Nader DA, Springmeyer SC, Elstad MR, Coxson HO, Chan A, et al. The IBV Valve trial: a multicenter, randomized, double-blind trial of endobronchial therapy for severe emphysema. J Bronchology Interv Pulmonol 2014; 21: 288-97.

14. Votruba J, Collins J, Herth FJ. Successful treatment of ventilator dependent emphysema with Chartis treatment planning and endobronchial valves. Int J Surg case Rep 2011; 2: 285-7.

15. Lee P, Khoo KL. A review of current bronchoscopic interventions for obstructive airway diseases. Ther Adv Respir Dis 2012; 6: 297-307.

16. Shah PL, Herth FJ. Current status of bronchoscopic lung volume reduction with endobronchial valves. Thorax 2014; 69: 280- 6 .

17. Gompelmann D, Herth FJ, Slebos DJ, Valipour A, Ernst A, Criner GJ, et al. Pneumothorax following endobronchial valve therapy and its impact on clinical outcomes in severe emphysema. Respiration 2014; 87: 485-91.

18. Valipour A, Slebos DJ, de Oliveira HG, Eberhardt R, Freitag L, Criner GJ, et al. Expert statement: pneumothorax associated with endoscopic valve therapy for emphysema--potential mechanisms, treatment algorithm, and case examples. Respiration 2014; 87: 513-21.

19. Deslee G, Klooster K, Hetzel M, Stanzel F, Kessler R, Marquette CH, et $a l$. Lung volume reduction coil treatment for patients with severe emphysema: a European multicentre trial. Thorax 2014; 69: 980-6.

20. Deslee G, Barbe C, Bourdin A, Durand-Zaleski I, Dutau H, Jolly D, et al. [Cost-effectiveness of lung volume reduction coil treatment in emphysema. STIC REVOLENS]. Rev Mal Respir 2012; 29: 1157-64.

21. Refaely Y, Dransfield M, Kramer MR, Gotfried M, Leeds W, McLennan G, et al. Biologic lung volume reduction therapy for advanced homogeneous emphysema. Eur Respir J 2010; 36: 20-7.

22. Magnussen H, Kramer MR, Kirsten AM, Marquette C, Valipour A, Stanzel F. Effect of fissure integrity on lung volume reduction using a polymer sealant in advanced emphysema. Thorax 2012; 67: 302-8.

23. Snell GI, Hopkins P, Westall G, Holsworth L, Carle A, Williams TJ. A feasibility and safety study of bronchoscopic thermal vapor ablation: a novel emphysema therapy. Ann Thoracic Surg 2009; 88: 1993-8.

24. Gompelmann D, Heussel CP, Eberhardt R, Snell G, Hopkins P, Baker K, et al. Efficacy of bronchoscopic thermal vapor ablation and lobar fissure completeness in patients with heterogeneous emphysema. Respiration 2012; 83: 400-6.

25. Choong CK, Cardoso PF, Sybrecht GW, Cooper JD. Airway bypass treatment of severe homogeneous emphysema: taking advantage of collateral ventilation. Thorac Surg Clin 2009; 19: 239-45.

26. Shah PL, Slebos DJ, Cardoso PF, Cetti E, Voelker K, Levine B, et al. Bronchoscopic lung-volume reduction with Exhale airway stents for emphysema(EASE trial): randomised, sham-controlled, multicentre trial. Lancet 2011; 378: 997-1005.

How to cite this article: Hou G. Bronchoscopic lung volume reduction in chronic obstructive pulmonary disease: History and progress. J TransI Intern Med 2015; 3: 147-150. 